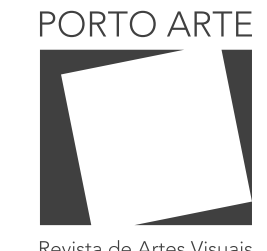

Revista de Artes Visuais

v. 25 n 44 $\mathrm{Jul} / \mathrm{dez} 2020$ e-ISSN: 2179-8001

\title{
Arte e resistência micropolítica: o museu-clínica como exercício de hospitalidade ${ }^{1}$
}

Art and micropolitical resistance: the museum-clinic as an exercise of hospitality

\section{Luiza Proença}

ORCID: 0000-0002-3496-839X

Pontifícia Universidade Católica de São Paulo, Brasil

\section{Resumo}

Em torno da ideia de hospitalidade, o ensaio investiga a possibilidade de políticas no campo da arte que se desloquem dos hábitos acomodados de assimilação de diferenças em direção a dinâmicas mais atentas às vidas que pulsam dentro e fora das instituições artísticas, como forma de resistência à cultura de hostilidade e repressão. Este deslocamento é pensado com a ajuda da documentação do Congresso de Psicodrama realizado no Museu de Arte de São Paulo, em 1970, um evento que esboçou o museu-clínica, sugerindo a instauração de processos simultaneamente clínicos, políticos, éticos e estéticos e de análise institucional.

Palavras-Chave

Arte. Museu. Clínica. Hospitalidade. Resistência.

1- Uma versão deste ensaio integra minha dissertação "Políticas da arte, ética de vida", redigida no Programa de PósGraduação em Psicologia Clínica no Núcleo de Subjetividades da PUC-SP, 2020. Algumas das ideias aqui apresentadas também foram publicadas em um breve ensaio em inglês

e polonês pela revista Obieg [online], Varsóvia: Ujazdowski Castle Centre for Contemporary Art, n.11, 2019.

\section{Abstract}

From the idea of hospitality, the essay investigates the possibility of politics in the art field that could move from the accommodated habits of assimilation towards dynamics more attentive to the lives that pulsate inside and outside art institutions, as a form of resistance to the culture of hostility and repression. This movement is thought through the documentation of the Psychodrama Congress held at the São Paulo Art Museum, in 1970, an event that outlined the museum-clinic, suggesting the establishment of processes of institutional analysis and that involves, simultaneously, a clinical, political, ethical, and aesthetic dimension.

Keywords

Art. Museum. Clinic. Hospitality. Resistance. 


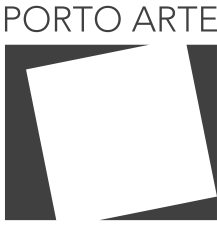

Revista de Artes Visuais

$\vee 25 n .44$

$\mathrm{Jul} / \mathrm{dez} 2020$ e-ISSN: 2179-8001

São Paulo sempre me foi hostil. Em minha própria terra, temo ter meu corpo sob uma lápide de concreto quente, condenado ao ruído de automóveis particulares e de ônibus superlotados. Entre nomes de rua de gente que não conheço, ando rápido e focada. Me percebo também hostil: agressiva, neurótica, ansiosa, trabalhadora, competitiva, consumidora, narcísica, indisposta, sem tempo, uma anfitriã avarenta. Mas é também caminhando que encontro brechas, redimensiono as escalas e estabeleço relações mínimas de pertencimento. Entre essas andanças a pé, os trajetos acompanhando marchas coletivas me ajudaram a entender o direito de estar no espaço público, de circular pela cidade e de acessar lugares centrais - incluindo parques, cinemas, museus - que antes me eram desconhecidos ou me pareciam distantes demais. 0 direito de desnaturalizar a hostilidade, reivindicar a hospitalidade e reinventar a cidade que me é externa e interna.

No início de 2003, encontrei algumas amigas no vão do Museu de Arte de São Paulo, o Masp, e caminhamos em direção ao parque Ibirapuera e ao consulado dos Estados Unidos, em um ato contra a guerra no Iraque. A Guerra ao Terror desencadeada em resposta aos ataques de 11 de setembro de 2001 instaurou, sem que nos déssemos conta, um sistema abusivo de vigilância global. Diante do medo de uma suposta ameaça terrorista - do "Outro" estrangeiro ou insurgente -, a vida política gerou uma crise de hospitalidade que, forjada como conceito essencial numa sociedade democrática e progressista, é interpretada em termos de "tolerância" para com esse "Outro" que deve ser pacificado, educado e assimilado, sob o crivo de uma operação discriminatória entre "amigos" e "inimigos". Em escala doméstica, através da internet e das redes sociais, estimulamos comportamentos hostis, além de contribuir involuntariamente com dados e privacidade, imersos em um processo de controle social sem precedentes.

Naquele dia, no vão do Masp, esperando a saída do ato, me dei conta de que eu não sabia exatamente o que havia ali dentro do Museu. Lembrava vagamente de algumas pinturas expostas em luz baixa sendo comentadas por vozes também baixas: um retrato por Picasso, o filho do carteiro do Van Gogh, as meninas com rosto de boneca de porcelana da Rosa e azul de Renoir - de fato, entre as mais célebres da coleção. No entanto, na maior parte da minha vida, vi o Masp como monumento urbano. Recorrentemente, pessoas perguntam se aquele prédio é mesmo um museu ou se é mais um comum escritório comercial da Avenida Paulista. Museus são também, muitas vezes, comparados à necrotérios, lugares de objetos mortos e em desuso. Se o Masp pode ser visto como mausoléu suspenso, sob ele há, porém, uma vida pulsante, ainda que frágil, a ser exumada. Lá é ponto de encontro para rolê, teto para se proteger da chuva, é casa de gente, território para protestar.

\section{Dentro e fora do museu}

Lina Bo Bardi dedicou grande parte de sua vida pensando sobre a função dos museus na realidade social do Brasil, afastando-se de uma herança europeia conservadora. Ela se formou profissionalmente na Itália do final da década de 1930, onde conheceu seu marido Pietro Maria Bardi, cuja relações com o fascismo da época são 


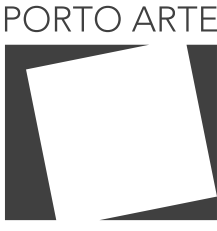

Revista de Artes Visuais

$\vee 25 n .44$

$\mathrm{Jul} / \mathrm{dez} 2020$ e-ISSN: 2179-8001

recorrentemente tratadas por historiadores. Em 1946, o casal pretendia se mudar para a Argentina, como fizeram muitos alemães e italianos da extrema-direita no pós-guerra, mas, ao final, decidem ficar no Brasil para contribuir com o magnata Assis Chateaubriand na fundação do Masp.

Ao conceber o edifício para a sede do Masp, inaugurada em 1968 na Avenida Paulista, Lina afirmou que queria criar uma "arquitetura ruim", com espaços livres que pudessem ser criados coletivamente (ROLNIK, 2013). Com uso do vidro e da criação de áreas abertas à cidade, as pessoas seriam incentivadas a habitar ativamente os espaços internos, criando uma relação contínua entre o que acontece dentro e o fora do Museu, como uma fita de Moebius. Ao estimular a convivência, Bo Bardi esperava que elas visitassem as exposições impulsionadas por sua própria iniciativa e vontade genuína. Portanto, a experiência do Masp envolve uma dimensão pública essencial para uma instituição que, embora privada, visou estabelecer uma relação não autoritária com seus públicos.

Muitas das proposições originárias de Lina se perderam ao longo dos anos, principalmente a partir dos anos 1990, quando o Masp adotou outras políticas institucionais, como, por exemplo, cobrir as janelas de vidro com paredes de gesso. Em 2015, como parte de uma nova direção artística, colaborei em um projeto focado na reflexão e resgate de acervos, arquivos e arquitetura do Museu, além de assumir a curadoria dos seus programas públicos e de mediação. Ao mesmo tempo que eu estabelecia, pela primeira vez, uma relação mais íntima com o interior do Museu, a espécie de arqueologia institucional que era feita arquitetonicamente revelava, pouco a pouco, as vistas para o seu exterior. Passei a ter, então, um novo ponto de vista da rua e dos protestos que ali ocorriam, de dentro da instituição. Também uma maneira particular de escuta, pois os discursos e gritos dos manifestantes ressoavam por todos os andares do edifício, perturbando a concentração no trabalho. No momento de crescente crise e polarização política que se agravou naquele ano de 2015 , indagar sobre as posições que o Masp e outras instituições culturais poderiam tomar diante daquela reviravolta política, e qual seria sua função como arena pública, se tornou uma constante. Como escutar de maneira responsiva essas vozes externas, ora mais graves, outras mais frágeis; ora reativas, outras mais pulsionais? Afinal, quão porosa pode ser a instituição artística - como lugar de criação, de memória e de elaboração simbólica - de modo a acolher corpos insurgentes e experiências coletivas, atentando para a vida que vibra fora e dentro dela? Como o território da arte poderia romper com a hostilidade da cidade, driblar a cultura de repressão, o estado policial e a ideologia neoliberal baseada na tolerância e assimilação?

Entre o Picasso, o Van Gogh e o Renoir, pude conhecer no Masp centenas de outras obras e documentos, incluindo esculturas, vídeos, vestuário, objetos, fotografias e cartas, oriundas de uma variedade de regiões geográficas e períodos, e que retratam realidades diversas. Partindo desse próprio acervo histórico, a documentação de um evento realizado no Museu há cinquenta anos ajudará a pensar problemas latentes no presente. 


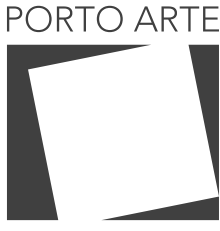

Revista de Artes Visuais

$\vee 25 n .44$

$\mathrm{Jul} / \mathrm{dez} 2020$ e-ISSN: 2179-8001

\section{Museu-clínica}

Lina tinha uma relação estreita com o teatro político. Na Bahia, no final dos anos 1950, ela desenvolveu uma intensa parceria com o diretor de teatro Martim Gonçalves e o cineasta Glauber Rocha. Ela desenhou a cenografia para peças de Brecht e Camus e, nos anos 1980, renovou o espaço do Teatro Oficina no bairro do Bexiga, em São Paulo. De acordo com o diretor José Celso Martinez Correa, o auditório grande do Masp foi inspirado em $O$ teatro e seu duplo, de Antonin Artaud $^{1}$. A larga escada de concreto no Vão Livre, que leva os visitantes aos espaços expositivos, foi projetada como um palco ou palanque para vários atos performáticos e políticos ${ }^{2}$. Na pinacoteca do Masp, os cavaletes de vidro usados como suporte para as pinturas evocam uma "consciência brechtiana", ao revelarem a estrutura da moldura e o verso dos quadros.

Também no Masp, Lina elaborou a cenografia do primeiro Congresso de Psicodrama no Brasil ${ }^{3}$, que aconteceu em agosto de 1970. Proposto por um grupo de psicodramatistas em formação, o Congresso é considerado não somente um "ato fundador do psicodrama brasileiro"4 (CEPEDA e MARTIM, 2010, p. 27), mas também um evento crucial para a psicologia no Brasil, ao oferecer uma alternativa mais politizada ao então monopólio de uma psicanálise conservadora restrita às elites. O livro Masp 1970: O psicodrama, de Norival Albergaria Cepeda e Maria Aparecida Fernandes Martin (2010), reúne depoimentos de participantes do Congresso, em sua maioria descrevendo-o como um happening ou ação de resistência coletiva à ditadura civil-militar no Brasil, no ápice de sua repressão: "se a ditadura decretava o isolamento, ali [no Congresso] se organizava um encontro; se o poder impedia as manifestações, a nova proposta, insurgente, as reconhecia e estimulava" (CEPEDA e MARTIM, 2010, p.124). Encontro, troca, alegria, curiosidade, afeto, celebração, encantamento, criação - estas e outras palavras entusiasmadas são usadas para relatar o vibrante ambiente propiciado pelo Congresso, que criou um respiro na política de proibição e no sentimento de medo presentes no cotidiano extramuros do Masp, mesmo sob a ameaça do evento ser fechado por policiais infiltrados ou pelo Comando de Caça aos Comunistas. Em seu depoimento, Antônio Carlos Cesarino afirma: "num período em que tudo era perigoso, penoso e limitado, surgiu subitamente diante de um grupo de jovens não apenas uma alternativa dentro da formação psicoterápica, mas um mágico espaço desalienante e libertador" (CEPEDA e MARTIM, 2010, p.51).

\footnotetext{
1- Essas ideias foram retomadas por integrantes do Teatro Oficina, em atividade organizada por ocasião da exposição Avenida Paulista, no Masp, em 2017.

2- De acordo com Raquel Rolnik, Lina relatou em depoimento de vídeo gravado em 1972: "Assim nasceu o grande belvedere do Museu, com a escadinha pequena. A escadinha não é uma escadaria áulica, mas uma escadinha-tribuna que pode ser transformada em um palanque". (ROLNIK, 2013)

3- Trata-se do V Congresso Internacional de Psicodrama, tendo sido esta a primeira vez em que foi realizado no Brasil, juntamente com o I Congresso Internacional de Comunidade Terapêutica. O I Congresso aconteceu em Paris, em 1964, e o último, em Tóquio, em 1972. Entre os vários desdobramentos do Congresso, está o Psicodrama no Centro Cultural São Paulo, ativo todos os sábados, desde 2003.

4- As origens do psicodrama no Brasil, no entanto, remetem à prática pontual de Alberto Guerreiro Ramos, nos anos 1940. No Instituto Nacional do Negro, de Abdias do Nascimento, no Rio de Janeiro, Guerreiro Ramos dirigiu e organizou seminários envolvendo o psicodrama, privilegiando questões étnico-raciais que muito provavelmente, ficaram de lado na participação majoritária de profissionais brancos no Congresso de São Paulo, na década de 1970.
} 


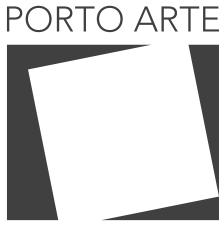

Revista de Artes Visuais

v $25 n .44$

Jul/dez 2020 e-ISSN: 2179-8001

O evento ganhou muita visibilidade, inclusive na mídia, e representou a maior reunião pública em São Paulo naquele ano. Com a presença de cerca de três mil pessoas, provocou um incomum congestionamento de carros na Avenida Paulista. Aberto a quaisquer interessados, o Congresso juntou não somente psicólogos e os mais influentes psicodramatistas do mundo, mas também atores, sociólogos, filósofos, pedagogos e artistas ${ }^{5}$.

O psicodrama surgia também como um movimento político-cultural. Como método, ele propõe atividades em grupo baseadas na expressão de situações-problemas através da linguagem teatral, introduzindo assim a linguagem artística ao trabalho clínico. Além disso, o desejo de seu fundador, Jacob Levy Moreno, também era o de tirar a psicoterapia dos consultórios e dos hospitais, propondo que ela fosse feita em qualquer espaço público, como escolas, praças e - por que não? - museus e centros culturais.

Foi a proximidade de Moreno com a filosofia política que fez Lina autorizar a realização do Congresso no Masp. Ela se engajou no projeto "com entusiasmo e comprometimento, pois faziam parte de sua personalidade a irreverência e o sonho de ver a arte em comunhão com a comunidade. Era uma psicodramista" (CEPEDA e MARTIM, 2010, p. 67). Tornando-se responsável pela cenografia do evento, a arquiteta instalou um grande teatro de arena com uma arquibancada na forma de ferradura no segundo subsolo do Museu, um espaço originalmente pensado para ser um teatro popular, mas que, por solicitações da prefeitura de São Paulo, foi mantido como um salão para eventos sociais (chamado de "hall cívico"). Nos tapumes que serviam de estrutura para o ambiente do Congresso, ela pintou em vermelho frases significativas do livro de Moreno, As palavras do pai (1920), mas elas foram apagadas antes de o evento ser inaugurado, para que não chamassem atenção da censura. Seis salas ou anfiteatros móveis acolheram encenações feitas em "discussões dramatizadas", "ateliers de expressão" e outras atividades, abordando temas variados que incluíam relações interpessoais e conflitos individuais e coletivos (CEPEDA e MARTIM, 2010, p. 67).

Introduzindo uma prática terapêutica, pedagógica, criativa e libertária, o Congresso de Psicodrama representou, para Cepeda e Martin, um contraponto à forte repressão política do momento, à psicanálise e, acrescente-se, ao museu tradicional. Ao mobilizar forças vitais e o pensamento por meio do corpo coletivo, incentivou dinâmicas instituintes em substituição às velhas formas instituídas (CESARINO apud CEPEDA e MARTIM, 2010, p. 108), seja no campo das áreas psi ou na arte. Maria Alicia Romaña lembra que, com o território da arte oferecido pelo Masp, no Congresso, era inevitável que não se comentasse a Bienal de arte que havia ocorrido no ano anterior, em 1969 (ROMAÑA apud CEPEDA e MARTIM, 2010, p. 125-126), conhecida como "Bienal do Boicoite" por conta da recusa de vários artistas internacionais em participar como protesto contra a ditadura. Mesmo com tantos diálogos entre o Congresso de Psicodrama e a arte, nada se escreveu sobre a sua relevância para o contexto artístico, tendo sua documentação

5- Entre as figuras presentes, estava o sociólogo francês Georges Lapassade e o grupo estadunidense de teatro experimental, Living Theater. No entanto, o criador do psicodrama, Jacob Levy Moreno, então com 81 anos, não esteve presente, em razão de algumas divergências entre os organizadores. 


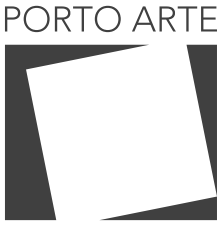

Revista de Artes Visuais

$\vee 25 n .44$

$\mathrm{Jul} / \mathrm{dez} 2020$ e-ISSN: 2179-8001

esquecida nos arquivos tanto do Masp como do Instituto Lina Bo e PM Bardi. Ou seja, se naquela ocasião o espaço museológico se conectava com o corpo, a subjetividade, ou a vida, tal conexão parece ter se perdido. Ao praticar o psicodrama dentro de um museu, o Congresso esboçava o museu-clínica - um lugar de escuta, acolhimento, mediação e criação de processos de subjetivação; com uma função clínica-política-estética. O museu-clínica, como espaço de resistência e liberdade, poderia ser reativado, especialmente perante a atual conjuntura social-subjetiva brasileira, autoritária e hostil, remanescente do passado colonial escravocrata - um trauma que jamais foi elaborado e que vem se repetindo desde a fundação do país, não só no Estado (como na ditadura militar e no atual governo federal), mas no próprio modo de subjetivação dominante. 0 desafio que se coloca é investigar o que seria, hoje, a dimensão clínica como exercício de hospitalidade no projeto do museu e suas consequências para o território da arte, analisando o modo como ele se articula no mundo globalizado.

\section{A revanche ou o desmanche do território}

Hospitalidade pressupõe um lugar, um espaço onde é possível receber alguém de fora, de outro lugar ou sem lugar. Pode ser um país, uma instituição, uma casa, e até mesmo um corpo. Aqui, trataremos lugar como território, um componente indissociável de todos os processos sociais, um todo dinâmico fundamental para o exercício da vida.

Para o geógrafo Milton Santos (2007), é pelo uso do território - habitado, reunindo chão e identidade - que são produzidos sentimentos de pertencimento e se formam comunidades nas quais interações e trocas são realizadas. Em um sentido, o território é a base do Estado-nação, que introduziu uma noção jurídico-política derivada da conquista do mundo a ser conhecido (SANTOS, 1998, p.15). No processo de colonização, o Estado-nação brutalmente estabeleceu relações de propriedade que não existiam nas formas de vida não modernas, ao mesmo tempo que transformou pessoas em hóspedes em sua própria terra, esta transformada em território. Exemplo disso são as populações ameríndias, para as quais a terra não é algo que lhes pertence, pois são elas que pertencem a ela, ou seja, o direito a terra é uma questão existencial. Assim, em outro sentido, o território também se tornou centro das reivindicações dos movimentos indígenas, quilombolas, das favelas e de outros grupos sociais, pois é "fundamental para afastar o risco de alienação, o risco da perda de sentido da existência individual e coletiva, o risco de renúncia do futuro" (SANTOS, 1998, p.15). No Brasil, porém, esses grupos seguem sendo alvos das mais variadas formas de violência como meio de reapropriação dos lugares em questão. De modo menos evidente, uma dessas formas de violência reside na "cordialidade" descrita por Sérgio Buarque de Holanda (1936) como espécie de mito fundador da subjetividade das classes dominantes brasileiras. Como donas de casa, patriarcas ou proprietárias, essas classes detêm o poder da hospitalidade e, portanto, o poder de definir as relações sociais e criar dependências existenciais, políticas e econômicas. Pela cordialidade, dotada de polidez, esquivam-se de conflitos, mantendo decisões de interesse público reservadas à esfera do íntimo e do familiar. 


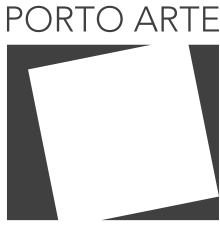

Revista de Artes Visuais

v. 25 n. 44

$\mathrm{Jul} / \mathrm{dez} 2020$ e-ISSN: 2179-8001

O conceito de hospitalidade é chave na formação de várias sociedades resultantes do processo colonial. O curador Bonaventure Soh Bejeng Ndikung (2018) afirma que, no entanto, hospitalidade é como um "ato esquizofrênico", pois abrange tanto uma abertura para o convidado sentir-se em casa como uma repulsa em relação a ele, sem a possibilidade real de compartilhamento da propriedade 6 . Diante dessa configuração, "o hóspede, portanto, será sempre um hóspede e estará sempre em estado de limbo, exceto em casos como o colonialismo, onde o hóspede vem com o poder de repressão, denigração, desapropriação e desumanização" (SOH BEJENG NDIKUNG, 2018, p.4).

Com sentido similar ao de Soh Bejeng Ndikung, a noção de "esquizofrenia" é também sugerida por Santos para diagnosticar o complexo arranjo de forças em torno do território - arranjo ao qual se somaram a força do capitalismo financeirizado e seus fluxos transnacionais, intensificados pelas mais recentes tecnologias de comunicação que vão constituindo novas subjetividades globais. Para ele, não há neutralidade nem passividade no território:

\footnotetext{
O território tanto quanto o lugar são esquizofrênicos, porque de um lado acolhem os vetores da globalização [e da privatização do espaço comum], que neles se instalam para impor sua nova ordem, e, de outro lado, neles se produz uma contraordem, porque há uma produção acelerada de pobres, excluídos, marginalizados. (SANTOS, 2001, p.114)
}

Pela expropriação dos bens naturais e da força de trabalho de todos os territórios possíveis, o capital desintegra fronteiras, bem como desagrega e desorganiza comunidades, em direção a uma livre circulação. No mundo globalizado, a expectativa é que os lugares estejam unidos e sejam interdependentes, funcionando como suportes de uma rede que verticaliza as relações e transporta valores. Como resistência a essa verticalidade, Santos (1998) defende a ampliação e criação de uniões horizontais, de modo a ativar o território via um acontecimento solidário, impondo ao mundo uma revanche.

Em Mil platôs: capitalismo e esquizofrenia, de Gilles Deleuze e Félix Guattari (1997), a ideia de território, e uma consequente esquizofrenia, é compreendida não simplesmente como um conjunto de arranjos e agentes, múltiplos e visíveis, que constituem uma cartografia social, mas como uma estrutura passível de ser desmanchada por forças, múltiplas e invisíveis, que afetam sua cartografia. Pelo uso de linhas, cores e posturas, a ação de demarcação de territórios, nesse sentido, se 


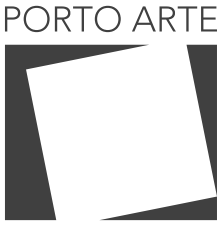

Revista de Artes Visuais

v. 25 ก. 44

$\mathrm{Jul} / \mathrm{dez} 2020$ e-ISSN: 2179-8001

aproxima dos gestos de criação artística7. Tais gestos de territorialização, envolvem inevitavelmente a dissidência, a elaboração de aberturas que permitam entradas alheias na "zona interior de domicílio ou de abrigo" ou saídas para a "zona exterior de domínio", para o seu fora (DELEUZE e GUATTARI, 1997, p.120-121) - uma dissidência que em nossa sociedade tende a ser patologizada ou até mesmo racializada, por colocar em xeque o modo de existência vigente. Os autores denominaram esse processo de desterritorialização, uma escapatória ao controle e à sujeição, para que, mais adiante, se possa reelaborar um novo território, com um novo agenciamento, em um movimento de reterritorialização. Resgatam, portanto, o território como lugar de produção incessante de modos de vida e de subjetividades.

0 que todos os autores referidos sugerem é que há resistência no território, este entendido como um lugar no qual a vida pulsa, sendo, portanto, fundamental para pensar formas de organização coletiva e práticas de hospitalidade. No entanto, a busca por essa resistência pode se dar tanto do interior do próprio território, como revanche dos "pobres, excluídos e marginalizados" que nele se encontram, ou então como desmanche ou processo de desterritorialização, de onde emergem cartografias ainda não existentes ou outros modos de existência. Partindo destes entendimentos, pode-se pensar como se dá a resistência e as práticas de hospitalidade no território da arte, considerando tanto as suas contradições quanto possíveis escapatórias que permitem criar outras cartografias culturais e modos de habitá-las.

\section{Arte e esquizofrenia}

0 território das artes visuais se encontra evidentemente imbricado nas contradições esquizofrênicas do mundo globalizado. E é assim que vemos Hito Steyerl, uma das mais celebradas artistas atuais, sugerir que, "se arte contemporânea é a resposta, a pergunta seria 'como o capitalismo poderia ser mais bonito'?" (STEYERL, 2012, p. 93, tradução minha). No ensaio Duty-Free Art, Steyerl discorre sobre os freeports de armazenamento de arte, zonas de livre-comércio isentas de impostos, localizadas em cidades como Singapura, Hamburgo, Mônaco e Pequim. Para ela, são como museus secretos, extraterritoriais ou deslocalizados; "a arte contemporânea se converte, assim, em representante dos bens comuns na ausência de chão, temporalidade ou espaço comum. É definida pela proliferação de localizações e pela falta de responsabilidade" (STEYERL, 2017, p. 139, tradução minha).

Por estruturar-se transnacionalmente, a arte contemporânea configura-se como "uma utopia do mercado de livre circulação" que, ao mesmo tempo, "perso-

\footnotetext{
7- "O que me fascina completamente são as questões de território e acho que Félix e eu criamos um conceito que se pode dizer que é filosófico, com a ideia de território. Os animais de território, há animais sem território, mas os animais de território são prodigiosos, porque constituir um território, para mim, é quase o nascimento da arte. Quando vemos como um animal marca seu território, todo mundo sabe, todo mundo invoca sempre... as histórias de glândulas anais, de urina, com as quais eles marcam as fronteiras de seu território. O que intervém na marcação é, também, uma série de posturas, por exemplo, se abaixar se levantar. Uma série de cores, os macacos, por exemplo, as cores das nádegas dos macacos, que eles manifestam na fronteira do território... Cor, canto, postura, são as três determinações da arte, quero dizer a cor, as linhas, as posturas animais são, às vezes, verdadeiras linhas. Cor, linha, canto. É a arte em estado puro" (DELEUZE, 1989).
} 


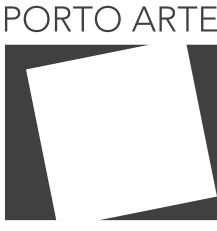

Revista de Artes Visuais

v $25 n .44$

Jul/dez 2020 e-ISSN: 2179-8001

nifica a contradição da mediação desse movimento pelo capital" (OSBORNE, 2013, p.27, tradução minha). Na forma de bienais, museus, residências, galerias, espaços independentes etc., as instituições de arte atuais funcionam como centros locais que orquestram relações globais entre os trabalhadores da arte - indivíduos que, apesar de transitarem constantemente, também carregam com eles os rótulos de suas posições geopolíticas. Por exemplo, enquanto bienais trazem em seus nomes suas localizações metropolitanas (como Bienal de São Paulo, Bienal de Istambul, Bienal de Veneza, e outras mais), os "born and lives" ["nasceu e vive"] ainda são destaques nas biografias dos profissionais da arte. Desta operação, surge uma forma temporária e superficial de hospitalidade, que se dá pela visita (de um artista ou curador, por exemplo, que fale inglês fluente e possa exercer um papel de representante sociocultural de seu local de origem), realizada a convite de um anfitrião (a instituição que, como um aeroporto, é um ponto de interconexão da rede global). Como resultado, amplia-se a rede, mas não se criam vínculos a longo prazo, uma vez que a circulação não deve ser interrompida. 0 convidado é somente bem-vindo em seu contato imediato, contribuindo para a utopia de uma sociedade democrática global. Ao mediar as relações de troca com trabalhadores da arte das mais variadas origens, as instituições de arte contemporânea acomodam e apropriam diferenças culturais ${ }^{8}$ (OSBORNE, 2013, p.165). Essa lógica, semelhante àquela de uma empresa neoliberal, vai moldando as subjetividades dos futuros trabalhadores que vão alimentar o sistema, demandando conteúdos, comportamentos e vocabulários específicos, ao mesmo tempo que formam, com características semelhantes, públicos abstratos.

Ao expor esse contexto, o filósofo Peter Osborne pergunta: "como a arte pode ocupar, articular, refletir criticamente e transfigurar um espaço nacional tão global?" (OSBORNE, 2013, p.28, tradução minha). 0 autor sugere que o único caminho é produzir algo que reflita sobre a própria construção do adjetivo "contemporânea" que designa a arte hoje - uma unidade fictícia de uma variedade de ideias sobre espaço e tempo projetada no presente. Steyerl, de maneira semelhante, pergunta que forma poderia ter uma nova instituição de arte pública, como um museu, considerando tanto a existência de espaços que armazenam obras de arte para sua valorização -as zonas francas - quanto de centros de arte que vêm acolhendo refugiados de nações em processo de desintegração ${ }^{9}$. Reformulando a pergunta a partir das reflexões feitas anteriormente: como poderia ser uma instituição de arte que considera a esquizofrenia que a atravessa, sem resultar na própria esquizofrenia, mas, sim, numa reconfiguração de sua cartografia sociocultural? Seria preciso incentivar políticas institucionais que, longe de domesticar as diferenças culturais, pudessem fazer delas oportunidades de criação de outras vivências de mundo, que já não seriam mais nem a de um anfitrião e sua regulação interna, nem a de um hóspede, com sua interferência, mas algo que germinasse entre elas.

8- Há, no entanto, uma diferença de relação: quando instituiçães de países mais pobres, como o Brasil. são anfitriãs de profissionais de países ricos, estes hóspedes têm maior poder de ação do que quando a operação se dá ao contrário.

9- Steyerl menciona o caso do Centro de Arte de Diyarbakir, na Turquia, que, em 2014, transformou-se em um abrigo para refugiados vindos do norte do Iraque após a ocupação das milícias do Estado Islâmico na fronteira com a Síria. Ao menos desde 2015, outras instituições de arte na Europa têm aberto seus espaços, de variadas formas, para refugiados. 


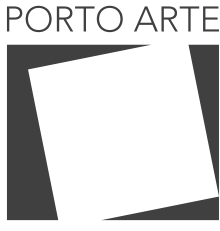

Revista de Artes Visuais

v $25 n .44$

Jul/dez 2020 e-ISSN: 2179-8001

\section{Dentro e fora do sujeito}

Em diversos ensaios sobre a produção da subjetividade e as políticas do desejo, Suely Rolnik descreve a relação entre as vivências dentro e fora do sujeito. Ela sugere imaginarmos o mundo projetado em uma fita de Moebius, uma superfície topológica-relacional com dois lados indistinguíveis: o familiar (pessoal) e o estranho (extrapessoal). Por meio desse exercício, Rolnik argumenta que a subjetividade não se limita ao sujeito e as formas de seu interior (aquilo que é familiar; marcado por hábitos, tradições e repertórios de representação sociocultural), mas é também a zona dos efeitos da presença viva das forças que são exteriores ao sujeito, das quais resultam estados desconhecidos que não tem imagem, palavra ou algo que os expresse, provocando estranhamento. Tais estados são portadores de embriões de futuro. A relação paradoxal entre estas duas vivências indissociáveis (as duas faces da superfície topológica-relacional que por, continuarem uma na outra, são uma só) desestabiliza a subjetividade, gerando tensão e mal-estar: por não poder ser traduzido nos repertórios culturais da face pessoal do sujeito, o estranho põe em xeque as imagens de si e do mundo pelas quais ela se orienta. 0 desejo é então convocado a criar algo em que a vida recobre equilíbrio em seu movimento (equilíbrio que é também existencial e emocional), de modo a dissolver o mal-estar. A resposta do desejo a esta demanda varia numa vasta gama de posições entre dois extremos: em um dos polos, um movimento reativo que consiste em conservar as formas atuais da subjetividade e seu modo de existência, suas crenças e linguagens estabelecidas, denegando os efeitos do outro e o mantendo como um corpo externo; no outro polo, um movimento ativo, no qual a subjetividade se sustenta no estranhamento e o desejo age criando as condições para que se complete a germinação dos embriões de mundo de que os efeitos das forças do outro na subjetividade são portadores. 0 que resulta do movimento ativo são mutações dos modos de existir, nos quais a vida recobra seu fluxo e sua potência.

A subjetividade, nas sociedades modernas-ocidentais-capitalistas-coloniais, tende ao movimento reativo que busca conservar um mundo que o sujeito vê como único e absoluto. Pois o que caracteriza o modo de subjetivação e a micropolítica do desejo dominantes nestas sociedades é a redução à face pessoal do sujeito e a obstrução do acesso à vivência da sua face extrapessoal: "quanto maior a desestabilização, mais veementemente o sujeito se encerra no que é estabelecido ou recebido, defendendo-o com unhas e dentes e empregando altos níveis de violência contra tudo que não é seu espelho para garantir sua permanência" (ROLNIK, 2017 , tradução minha). Ou seja, a existência real do outro é denegada e o sujeito com ele se relaciona como um objeto que Ihe é exterior e sobre o qual projeta representações. A invenção do conceito de "raça", no ocidente moderno, é inseparável desta dinâmica e, ao atribuir-Ihe uma comprovação supostamente científica, é usado para reproduzir a esterilidade na relação com o outro, o mantendo em um lugar fixo naturalizado como supostamente inferior e, com isso, justificar a desigualdade. Tal naturalização estende-se aos gêneros e às classes, e foi impulsionada pela museologia iluminista, cujas características ainda permanecem nas instituições contemporâneas, como será tratado mais pontualmente adiante. 


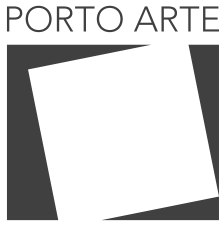

Revista de Artes Visuais

$\vee 25 n .44$

$\mathrm{Jul} / \mathrm{dez} 2020$ e-ISSN: 2179-8001

Se há uma reatividade dominante - que ensurdece, neutraliza, racionaliza, explica e conserva -, Rolnik (2018) argumenta a favor da ativação ou de uma reorientação ética que escute os afetos (ou seja, a presença viva do outro em seus efeitos no corpo), implicando-se com estes afetos e imaginando expressões que os tornem sensíveis, o que resulta numa transfiguração de si e de seu campo relacional. Na escala do sujeito, essa ativação é possível através de um saber próprio do corpo que, atento aos afetos, não lhe permite bloquear o mal-estar provocado pela desestabilização da tensão estranho/familiar. Dotado de um poder de avaliação das causas de desestabilização, esse saber-do-corpo, em exercício, aponta para aquilo que a vida requer para perseverar e se multiplicar em seu movimento. Considerando o corpo como território, propõe-se aqui pensar esse saber em termos de hospitalidade, uma hospitalidade ética, logo não reativa, que é potencializada por um trabalho clínico-analítico.

$\mathrm{Na}$ escala de um museu, a hospitalidade ética sustentaria as tensões que acontecem na fricção das formas internas que a instituição conserva com as forças externas que a atravessam, ou entre aquilo que já foi colecionado e o que não é capturável. Valendo-se de discursos de inclusão e transformação social, pelo acesso de um grande público (no singular), a maioria das instituições de arte ainda centraliza suas dinâmicas e conserva suas políticas internas, acordos e crenças - "inclusão", portanto, como micropolítica reativa ou integração em um modo de existência e visão de mundo de tudo o que dessas instituições diferem. A instauração de uma atenção clínica no museu, como a que propõe o psicodrama, possibilitaria, então, a emergência de alternativas aos modos coloniais e globais de pensar, produzir e compartilhar arte; de criações estéticas mais conectadas com a memória viva do corpo e não mortalizadas em objetos exibidos sob um sistema de vigilância de alta tecnologia.

\section{0 avesso museológico}

Instituições de arte contemporânea, por meio de seus programas pedagógicos e de exposição, têm o hábito de enunciar perguntas que acreditam ser relevantes socialmente, abordando os mais variados assuntos do presente. No entanto, nem sempre há ressonância nesse processo: a questão elaborada não vem necessariamente a partir de uma urgência local, além de ela raramente ser de fato debatida. Ou seja, muitas vezes, não existe uma questão ou inquietação baseada em uma demanda coletiva real; pautas mundiais são compartilhadas reprimindo quaisquer outros desejos e possibilidades de conflito. Há um tipo de encontro frequente nos circuitos de artes (e também nos acadêmicos) em que pessoas já influenciadas se mobilizam apenas para reforçar suas posições. Nada se aprende, e passa-se rapidamente para um próximo tópico.

Ao lado de empatia, solidariedade, cura, cuidado, entre outras noções, "hospitalidade" tem sido retomada como uma dessas pautas no circuito de arte, a partir da crise das políticas de imigração na Europa e Estados Unidos, e, em 2020, com nova relevância em meio à propagação da Covid-19. Seria incoerente, no entanto, tratar hospitalidade como um mero assunto predeterminado internamente, uma vez que a noção diz respeito a como estar atento para a questão de fora: como escutá-la, 


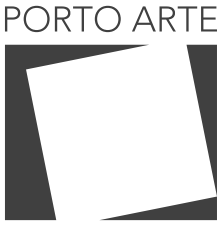

Revista de Artes Visuais

$\vee 25 n .44$

$\mathrm{Jul} / \mathrm{dez} 2020$ e-ISSN: 2179-8001

como recebê-la e dar-Ihe consequência. É assim que Jacques Derrida, em um jogo de linguagem, definiu a hospitalidade como "a questão da questão" (DERRIDA e DUFOURMANTELLE, 2003, p.27) - ou seja, a prática da hospitalidade implica abertura a um questionamento externo, que vem do estrangeiro, e coloca o sujeito-anfitrião em questão. No caso das instituições de arte, implica evitar temas sintetizados em um ciclo de programas, por exemplo. Em oposição à hospitalidade temporária e por convite, portanto condicional, seria preciso estimular uma hospitalidade incondicional, nos termos de Derrida, uma abertura para quem chega como um anônimo desconhecido, um visitante ou situação não identificável e imprevisível (DERRIDA e DUFOURMANTELLE, 2003, p.69). Mais do que isso, estimular uma micropolítica ativa ou hospitalidade ética, como anteriormente proposto, de modo que qualquer estrangeiro seja não simplesmente acolhido, mas que sua presença provoque encontros férteis e novas criações - seria esta uma importante ação da arte.

Tendo em vista a heterogeneidade e a emergência de novas existências, hospitalidade é também um conceito fundamental nas filosofias africanas. A palavra nguni bantu ubuntu - o "sou porque nós somos", que se tornou lema das políticas públicas propostas por Marielle Franco - é um componente vital nos entendimentos de pessoa e comunidade, definindo o indivíduo em termos de suas relações com os outros: uma pessoa se faz através de outras pessoas (GATHOGO, 2008). No entanto, enquanto ubuntu parece sugerir uma troca mais dinâmica entre envolvidos, Derrida parece desconsiderar em sua reflexão a possibilidade de anfitrião e hóspede alternarem a posição. Ou seja, mesmo a hospitalidade sendo incondicional, ela é exercida por anfitriões eternos, o que implica uma prática colonial de apagamento das subjetividades políticas dos hóspedes, eles também eternos (HILAL, 2019).

Considerando todos esses apontamentos teóricos, praticar a hospitalidade ética em uma instituição de arte significa, por exemplo, estabelecer uma política cultural oposta à orientação estritamente unidirecional em relação aos públicos. Isso implica reconhecer os visitantes não como uma massa homogênea e abstrata a ser educada a partir de uma oferta cultural, mas como contrapúblicos que podem intervir em sua programação e seus discursos ${ }^{10}$.

Um exercício de escuta desses contrapúblicos foi feito pelo núcleo de Mediação e Programas Públicos do Masp, do qual fiz parte, entre 2016 e 2017. Uma série de encontros semanais, em forma de conversas e oficinas, foi organizada com os funcionários

\footnotetext{
10- O conceito de contrapúblicos surgiu em resposta à exclusão da agência de grupos subalternos na definição de esfera pública de Jurgen Habermas em A mudança estrutural da esfera pública (1962). Nancy Fraser, por exemplo, argumenta que os contrapúblicos contestam "as normas excludentes do público burguês, elaborando estilos alternativos de comportamento político e normas alternativas de discurso público" (FRASER, 1990, p. 61, tradução minha). Ela também afirma que "as próprias esferas públicas não são espaços de grau zero de cultura, igualmente hospitaleiras a qualquer forma possível de expressão cultural. Em vez disso, consistem em instituições culturalmente específicas [...] que filtram e alteram os enunciados que enquadram; elas podem acomodar alguns modos expressivos e outros não" (FRASER, 1990, p. 69, tradução minha).
} 


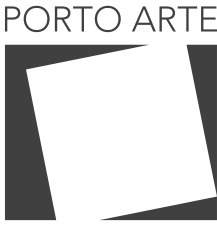

Revista de Artes Visuais

$\vee 25 n .44$

Jul/dez 2020 e-ISSN: 2179-8001

denominados "Orientadores de Público"11. Era um grupo de cerca de 35 pessoas, formado por estudantes universitários (contratados como estagiários e, em geral, mais jovens) e também pessoas sem educação formal completa (com contrato fixo e, em geral, mais velhos, racializados e residentes em bairros periféricos, sendo que alguns estavam vinculados ao Museu a mais de uma década). Recentemente, também havia sido implementada uma política de diversidade que resultou na contratação de imigrantes, travestis e pessoas trans. Esses funcionários e funcionárias se revezavam entre os espaços expositivos e as áreas internas do Masp, e suas atribuições incluíam dar as boas-vindas aos visitantes na recepção, receber bolsas no guarda-volumes, responder dúvidas gerais, salvaguardar as obras, controlar fluxos e dar apoio aos eventos. Eles recebiam um "treinamento" inicial sobre hospitalidade e postura, mas nenhuma formação sobre a história do Masp, o acervo, as atividades dos demais departamentos, os conceitos que permeavam a programação, e tampouco tinham espaço para falar das experiências diárias na instituição. Com salários menores, os Orientadores de Público tinham escalas de trabalho superiores às demais equipes e, ao mesmo tempo, eram os únicos a ter contato permanente com os visitantes. A iniciativa dos encontros surgiu, primeiramente, tanto para criar um espaço de formação e diálogo quanto para tornar seus trabalhos e cotidianos menos alienantes, de modo que suas presenças naquele ambiente (como elas o afetam e como são afetadas por ele) pudessem ser percebidas e levadas em consideração nos rumos do Museu, como no exemplo a seguir.

Embora a visitação seja crucial para a função pública e social de um museu, o Centro de Documentação do Masp, assim como os arquivos de outras instituições, preserva somente os documentos que representam a perspectiva curatorial ou da imprensa. Vigiando as obras ou sendo vigiados, os Orientadores ou os visitantes são constantemente lembrados de que seus trabalhos, atos criativos e suas vidas não têm nenhuma importância em comparação com as dos consagrados artistas. Assim, posteriormente, a ideia era também documentar depoimentos desses funcionários sobre o Museu, bem como suas próprias produções criativas ou artísticas (muitos fotografavam, desenhavam, tocavam instrumentos, escreviam histórias e poesias, entre outras atividades). Com a ajuda deles, também foi possível registrar, em linguagens visuais e textuais diversas ${ }^{12}$, reações e expressões espontâneas dos visitantes (comentários diversos sobre obras, piadas, gestos corporais, usos variados das instalações etc.), chamando atenção para as zonas dos efeitos dos encontros entre as pessoas e o Museu, hóspedes e anfitriões.

\footnotetext{
11- Essa iniciativa foi impulsionada pela parceria com Cayo Honorato, professor da UnB, no projeto Another Road Map School for Art Education, proposto pela Zurich University of the Arts (ZhDk). O projeto envolveu toda a equipe de Mediação e Programas Públicos, com especial engajamento de Pedro Andrada e Leonardo Matsuhei, que produziram uma publicação denominada Zine dos Desorientadores, em 2018. Esta publicação foi distribuída entre todos os colaboradores e pode ser encontrada na Biblioteca e Centro de Documentação do Masp. Fundamental também foi o envolvimento das coordenadoras do núcleo de Eventos e Serviços, Suyanne Keidel e Leila Maria Silva.

12- Pequenos cadernos foram distribuídos para que os Orientadores pudessem fazer suas anotações diárias, desenhos e escritos. Em outras ocasiões, foram organizadas oficinas envolvendo técnicas como desenho e colagem. Alguns funcionários também preferiram enviar suas produções diretamente via mídias digitais, como fotografias e notas feitas por celular. Por fim, entrevistas para coletar depoimentos orais foram feitas com aqueles que não se sentiam tão confortáveis com os formatos anteriores.
} 


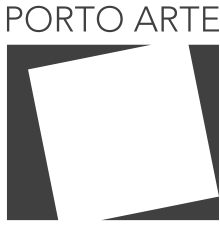

Revista de Artes Visuais

Entre os depoimentos coletados, há, por exemplo, o de Luiza B. do Nascimento, orientadora e poetisa, que fez, em forma de rima, um registro de uma conversa, também inventiva, que ouviu durante o seu expediente:

\footnotetext{
E assim os dias foram se passando e as visitas foram aumentando, à medida que muitos iam criando informações imoral, esse caso aconteceu com o Portinari e Tarsila do Amaral. O diálogo aconteceu entre dois jovens senhores que, sem nenhum pudor, criou rumores amorosos na vida particular desses dois pintores. Segue a conversa entre eles:

- Você sabia que na época Tarsila do Amaral e Portinari eram amantes?

- Mentira!? (se abismou o outro).

- Sim, e eles tinham um código entre eles, tá vendo nas pinturas do Portinari? Pés e mãos grandes?

- Sim, tô vendo (afirmou).

- Era esse o código. A Tarsila pintava pés e mãos grandes para se homenagearem.

Passei por entre eles na dúvida se eu permitiria tal heresia contaminar a cabeça daquele que estava ali a acreditar no que lhe convinha. E então, como se diziam que tudo na vida se copia, deixei fluir entre eles essa energia de autoria.
}

Instaurar a hospitalidade no contexto da arte requer acolher atos heréticos (heresia ou haerěsis, do latim: "escolha"), contrários ou diferentes de um dado sistema ou ordem; ou ainda, suspender a linguagem dominante ou discurso do mestre que caracteriza o espaço museológico, por sua atuação nas formações de significados e nas narrativas simbólicas. Se a clínica provoca uma dobra no discurso do mestre-analista-anfitrião, acessando o avesso deste discurso - o real -, como descreveu Lacan (1992), no museu, a escuta analítica, como ferramenta para hospitalidade, poderia ser usada de modo a desmantelar os mecanismos sistematizados de construção de imagens e de memória ${ }^{13}$. Em outras palavras, trata-se de um esforço de ver o invisível, ouvir o inaudível, de incidência no real e, portanto, de acessar o avesso museológico, criando transfigurações.

Colocar o museu sob o crivo analítico, portanto, subverte os processos de significação simbólica em direção ao que não tem imagem, nem ideia, nem representação alguma no espaço institucional. O museu-clínica estrutura-se na dinâmica do "agente duplo": sem descartar a linguagem do museu, com seu teor de recalque, procura o

\footnotetext{
13- Em The Museological Unconscious, Victor Tupitsyn afirma que o processo de museificação do mundo seria análogo ao estádio do espelho para a ordem simbólica de Lacan, na medida em que transfere a percepção do eu para os outros e vice-versa. Embora os primeiros museus tenham aparecido no final do século 18, para o autor, a origem da função museológica é antiga e misteriosa, revelando-se no interior dos indivíduos e da psique coletiva (TUPITSYN, 2009, p. 234).
} 


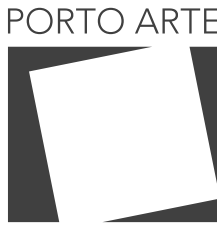

Revista de Artes Visuais

$\vee 25 n .44$

$\mathrm{Jul} / \mathrm{dez} 2020$ e-ISSN: 2179-8001

que está fora dos muros institucionais, introduzindo uma língua estrangeira ${ }^{14}$. A clínica faz do museu um agente-analista marcado pela escuta do inconsciente pulsional, daquilo não submisso a nenhuma autoridade ou sistema, que desconhece propriedade privada (SCHIAVON, 2019). Nessa escuta, há um processo de desterritorialização das condições do pensamento, reposicionando a instituição em um lugar de avaliação das coisas - incluindo o julgamento estético -, ainda não exercido. Quanto mais precisa a escuta, mais o discurso do mestre, que caracteriza o espaço museológico, se desinstala, dando lugar a um saber-fazer originário da arte na desarticulação de sintomas a partir de uma variedade de linguagens, dizeres, formas. Movimenta-se em direção à sublim/ação: a melhor ação possível, o exercício direto e destino da pulsão, sendo (obra de) arte e vida uma coisa só - faz da arte extemporânea, destinada a cobrir um tempo fora ou muitos tempos ${ }^{15}$. 0 museu-clínica provoca, portanto, uma reordenação ética do território da arte.

\section{Da crítica à análise institucional}

Praticar a hospitalidade no museu - sob um viés simultaneamente clínico, estético, político e ético - convoca a escuta clínica como uma metodologia de organização do trabalho cultural, capaz de aprimorar o discernimento e a tomada de decisões, reconfigurando a noção de responsabilidade institucional.

Trata-se de um processo diferente das práticas artísticas conhecidas como "crítica institucional", cuja emergência nos anos 1960 e 1970 tem estreita correlação com as revoltas anti-institucionais daquelas décadas. Sob a perspectiva das figuras autorizadas da produção artística, agentes de um campo cultural profissionalizado, a crítica institucional problematiza as funções sociais e contextos ideológicos dos espaços de arte, por meio de obras, boicotes à eventos, performances, encontros públicos, textos etc. como meios de intervenção. Resulta, na maioria das vezes, na institucionalização da própria crítica - um processo de reificação e exclusão de uma parte significativa dos funcionários mais precarizados nesses espaços, no qual a organização e os lugares de poder mantem-se os mesmos. Ainda hoje, é possível dizer que as instituições mantêm uma posição confortável, na medida que convidam terceiros para encontrarem soluções para questões que elas próprias não enfrentam internamente, oferecendo hospitalidade temporária. Com isso, asseguram uma aparência politicamente engajada, um capital cada vez mais valorizado no circuito de arte contemporânea.

Em contraponto à estratégia macropolítica da crítica institucional, uma prática de "protesto pragmático das consciências", a micropolítica do museu-clínica, como "protesto pulsional dos inconscientes" (ROLNIK, 2018, p.122), atenta ao cotidiano do próprio território da arte como lugar de vida; às relações materiais e imateriais que acontecem nele. Estabelecem-se processos coletivos, internos e por alianças

\footnotetext{
14- Em seus seminários, Lacan referia-se a essa pequena língua que se fala através da análise (e muitas vezes através da arte, quanto esta se encontra em sua função clínica) como "lalague". Podemos entendê-la como uma viagem estrangeira dentro da própria língua. 15 - Notas minhas das aulas de João Perci Schiavon ministradas no Programa de Pós-graduação em Psicologia Clínica da Pontifícia Universidade Católica de São Paulo, entre 2018 e 2019
} 


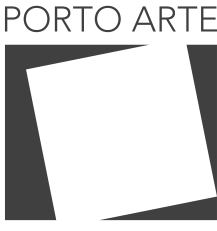

Revista de Artes Visuais

$\vee 25 n .44$

$\mathrm{Jul} / \mathrm{dez} 2020$ e-ISSN: 2179-8001

com outros grupos, que retomam o desejo no campo social e subvertem a alienação da divisão do trabalho na arte ${ }^{16}$.

Guattari reconhecia nas instituições unidades de produção de subjetividade cruciais na formação da conjuntura político-social. A partir de sua atuação na Clínica La Borde, na França, onde relata ter notado o impacto que a organização do trabalho poderia ter sobre a psicose, Guattari (1992) propõe a noção análise institucional como estratégia para enfrentar a normopatia cotidiana. Em La Borde, a execução das tarefas diárias do organograma de trabalho era realocada constantemente, fazendo "com que indivíduos e grupos se reapropriassem do sentido de sua existência em uma perspectiva ética e não mais tecnocrática" (GUATTARI, 1992, p.162). Por meio de uma dinâmica transversal e esquizoanalítica, há um remanejamento estrutural da instituição, de modo a favorecer uma minirrevolução interna que deve ter efeitos nos espaços externos, em relação aos seus usuários.

No museu, por exemplo, o grupo dominante constituído pelos curadores, os "coveiros do túmulo", impede a emergência da expressão da subjetividade inconsciente da instituição, composta também pelos demais funcionários. Reduzidos à face pessoal do sujeito, o que move a tomadas de decisão desses curadores nas instituições, em especial aquelas vinculadas à arte contemporânea, geralmente, "são os interesses exclusivamente narcísicos de seu ego em sua ânsia de reconhecimento e ascensão social" (ROLNIK, 2017b, p.72). Como levá-los a aceitar e até a solicitar que os questionem, sem que recuem diante do medo estarrecedor de despedaçar? O curador que renuncia à sua posição imaginária está, em compensação, apto a operar o recorte necessário da função curatorial em múltiplos encargos, implicando diferentes espécies de grupos e de pessoas. ${ }^{17}$ Assim como um analista, ele poderia suprimir recalcamentos, estando ele próprio vulnerável às forças ambientes em seu corpo. Como consequência, a programação do museu mobilizaria, em seus públicos, a mesma reconexão com o saber-do-corpo e de escuta (ROLNIK, 2017b, p.72), inserindo-se entre "os inconscientes que protestam" (DELEUZE e GUATTARI, 1992, p.34 apud ROLNIK, 2017b, p.47); entre os corpos insurgentes que mencionamos no início deste texto.

Diante de um crescente interesse em falar de hospitalidade em arte, torna-se necessário pensar no termo como prática distanciada da suposta tolerância ou cordialidade que amenizam as tensões existentes. Estabelecer uma dinâmica transversal, a partir de uma perspectiva clínica, no coração da organização do museu provavelmente resultaria em uma agenda menos autoritária e programática que, sensível aos processos, permitiria criar melhores formas de viver, alegres e menos hostis. Fazer do território da arte um lugar hospitaleiro demanda um esforço de longo prazo para desmontar

\footnotetext{
16- A "terceira onda" de crítica institucional, nos anos 1990 e 2000, chegou a se aproximar mais desta última perspectiva. Embora ainda centrado na figura dos artistas, Brian Holmes arrisca uma correlação da crítica institucional com a análise institucional e a transversalidade, conceitos desenvolvidos por Guattari. Cf. HOLMES, B. Investigações extradisciplinares: para uma nova crítica das instituições, Concinnitas, n. 12. Rio de Janeiro, UERJ, 2008 [online].

17- Parafraseando Guattari quando afirma, em relação à clínica: "O médico que renuncia à sua posição imaginária, para situar seu papel num plano simbólico, está em compensação apto a operar o recorte necessário da função médica em múltiplos encargos, implicando diferentes espécies de grupos e de pessoas" (GUATTARI, 1985, p. 99).
} 


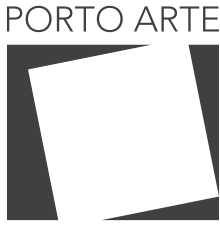

Revista de Artes Visuais

$\vee 25 n .44$ $\mathrm{Jul} / \mathrm{dez} 2020$ e-ISSN: 2179-8001

hierarquias em vários níveis, começando entre curador/faxineira e desdobrando-se na instituição/públicos. Requer um reconhecimento dos direitos de fala e escuta, em ser acolhido e acolher, de questionar e ser questionado. Muitas dessas práticas já são exercidas, por exemplo, pelos departamentos educativos de instituições, geralmente excluídos das prioridades curatoriais. Tempo e dedicação são necessários para que a instituição possa perceber suas próprias ignorâncias e transformar suas próprias políticas, estruturas, métodos, divisão de trabalho e conteúdos. É também dizer que não há hospitalidade sem disposição para re-instituir o território da arte.

\section{Referências}

CEPEDA, Norival Albergaria; MARTIN, Maria Aparecida Fernandes. MASP 1970: O Psicodrama. São Paulo: Agora, 2010.

DELEUZE, Gilles. O abecedário de Gilles Deleuze. 1989. [Transcrição de vídeo]. Disponível em: filosofia.seed.pr.gov.br. Acesso em: 10 mar. 2020.

DELEUZE, Gilles.; GUATTARI, Félix. O anti-Édipo. São Paulo: Ed. 34, 2010.

DELEUZE, Gilles.; GUATTARI, Félix. Mil platôs: capitalismo e esquizofrenia. São Paulo: Ed. 34, 1997. v. 4.

DERRIDA, Jacques; DUFOURMANTELLE, Anne. Da hospitalidade: Anne Dufourmantelle convida Jacques Derrida a falar da Hospitalidade. São Paulo: Escuta, 2003.

FRASER, Nancy, Rethinking the Public Sphere: a contribution to the critique of actually existing democracy. Social Text, Durham, no 25/26, p. 56-80, 1990.

GATHOGO, Julius. African Philosophy as Expressed in the Concepts of Hospitality and Ubuntu. Journal of Theology for Southern Africa, KwaZulu-Natal, v. 130, p. 39-53, mar. 2008.

GUATTARI, Félix. Caosmose: um novo paradigma estético. Rio de Janeiro: Ed. 34, 1992.

GUATTARI, Félix. Revolução molecular: pulsações políticas do desejo. Org. Suely Rolnik. 3. ed. São Paulo: Brasiliense, 1985.

HILAL, Sandi. The Right to Host. Overgrowth/ E-flux Architecture, Nova York, 25 set. 2019. Disponível em: https://www.e-flux.com/architecture/overgrowth/287384/the-right-to-host/. Acesso em: $10 \mathrm{dez} .2019$.

HOLMES, Brian. Investigações extradisciplinares: para uma nova crítica das instituições, Concinnitas, n. 12, Rio de Janeiro, UERJ, 2008 [online].

LACAN, Jacques. 0 seminário, livro 17: o avesso da psicanálise. Rio de Janeiro: Zahar, 1992.

OSBORNE, Peter. Anywhere or not at all: philosophy of contemporary art. Londres: Verso, 2013.

ROLNIK, Raquel. O MASP e a casa da sogra. Folha de São Paulo, São Paulo, Colunistas, 2 de dezembro de 2013. Disponível em: https://acervo.racismoambiental.net. br/2013/12/02 /o-masp-e-a-casa-da-sogra/. Acesso em: 20 out. 2020.

ROLNIK, Suely. Esferas da insurreição: notas para uma vida não cafetinada. São Paulo: n-1 Edições, 2018.

ROLNIK, Suely. O saber-do-corpo nas práticas curatoriais. Driblando o inconsciente co- 


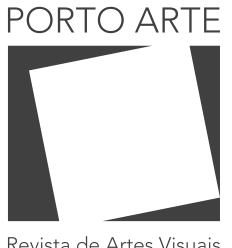

v. 25 n. 44 $\mathrm{Jul} / \mathrm{dez} 2020$ e-ISSN: 2179-8001
Ionial-capitalístico. In: MOTTA, Gabriela; ALBUQUERQUE, Fernanda (org.). Curadoria em artes visuais: um panorama histórico e prospectivo. São Paulo: Santander Cultural, 2017. p. 47-76. v. 1.

ROLNIK, Suely. The Spheres of Insurrection: suggestions for combating the pimping of life. E-flux Journal \#86, Nova York, nov. 2017. Disponível em: https://www.eflux. com/journal/86/163107/the-spheres-of-insurrection-suggestions-for-combating-thepimping-of-life/. Acesso em: 10 dez. 2019.

SANTOS, Milton. $O$ dinheiro e o território. In: Território, territórios: ensaios sobre o ordenamento territorial. 3. ed. Rio de Janeiro: Lamparina, 2007. p. 13-21.

SANTOS, Milton. 0 retorno do território. In: SANTOS, M.; SOUZA, M. A. Aparecida de; SILVEIRA, M. L. Território: globalização e fragmentação. São Paulo: Hucitec, 1998. p. 15-20.

SANTOS, Milton. Por uma outra globalização (do pensamento único à consciência universal). Rio de Janeiro: Record, 2001.

SCHIAVON, João Perci. Pragmatismo pulsional: clínica psicanalítica. São Paulo: n-1 Edições, 2019.

SOH BEJENG NDIKUNG, Bonaventure. Whose land have I lit on? Contemplations on the notion of hospitality. Berlim: Savvy Contemporary, 2018.

STEYERL, H. Duty-free art; Art in the age of civil war. Londres: Verso, 2017.

STEYERL, H. The Wretched of the Screen. Berlin: Sternberg Press/E-flux Journal, 2012.

TUPITSYN, Victor. The museological unconscious: communal (post)modernism in Russia. Cambridge/Mass: MIT Press, 2009. 


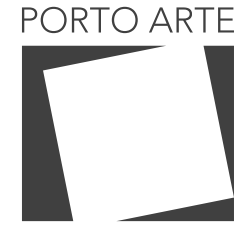

Revista de Artes Visuais

v. $25 n .44$ Jul/dez 2020 e-ISSN: 2179-8001

\section{Luiza Proença}

Pós-graduanda em Psicologia Clínica pelo Núcleo de Estudos da Subjetividade da PUC-SP, com bolsa CNPq.

Texto submetido em 22/12/2020

Texto publicado em 23/12/2020

Como citar: FREITAS, Maria Luiza Proença de. Arte e resistência micropolítica: o museu-clínica como exercício de hospitalidade. PORTO ARTE: Revista de Artes Visuais, Porto Alegre, RS, jul-dez. 2020. ISSN 2179-8001. 